\title{
EL ESPACIO Y LOS PERSONAJES VILLANESCOS EN ALGUNAS COMEDIAS URBANAS DE LOPE: TRADICIÓN, HIBRIDACIÓN Y OPORTUNISMO DRAMÁTICO*
}

\author{
Delia Gavela García (Universidad de la Rioja)
}

Cita Recomendada: Delia Gavela García, «El espacio y los personajes villanescos en algunas comedias urbanas de Lope: tradición, hibridación y oportunismo dramático», Anuario Lope de Vega. Texto, literatura, cultura, XXVIII (2022), pp. 7-36.

DOI: <https://doi.org/10.5565/rev/anuariolopedevega.438>

Fecha de recepción: 29 de junio de 2021 / Fecha de aceptación: 21 de julio de 2021

\section{RESUMEN}

El estudio del género urbano y de las comedias villanescas ha dado lugar a trabajos de referencia que marcan sus rasgos más destacados. Asimismo, se ha señalado la hibridación de ambos géneros, especialmente en las comedias tempranas del Fénix. En el presente trabajo se pretende analizar cómo Lope de Vega materializaba la integración de estos elementos en cinco comedias de dos fases diferentes de su producción: La serrana de Tormes, La serrana de la Vera y Los embustes de Celauro, anteriores a 1600, frente a La villana de Getafe y Al pasar del arroyo, redactadas en la segunda década del xvII. El análisis incluye la identificación de los rasgos genéricos de las obras, el desarrollo espacial de las mismas, para sopesar la preeminencia y alternancia de la ubicación urbana o rural, así como la funcionalidad dramática de la imbricación de ambos mundos, a partir de la integración de los personajes de la órbita urbana en la rural y viceversa.

Palabras Clave: Comedia urbana; comedia villanesca; espacio dramático; identidades fingidas; cronología; contexto socio-económico; tradición literaria.

ABSTRACT: Space and Rustic Characters in Some of Lope's Urban Comedies: Tradition, Hybridization and Dramatic Opportunism.

The study of the urban genre and villainous comedies have given rise to references that mark its most outstanding features. These studies have also noted the hybridization of both genres, especially in the early comedies of the Phoenix. This article aims to analyze how Lope de Vega embodied the integration of these elements in five comedies at two different stages of his production: La serrana de Tormes, La serrana de la Vera and Los embustes de Celauro, prior to 1600, compared to La villana de Getafe and Al pasar del arroyo, written in the second decade of the seventeenth century.

* Este trabajo se incluye en el marco del proyecto de investigación Fiestas teatrales en el Coliseo del Buen Retiro (1650-1660): Catalogación, estudio, edición crítica y recreación virtual, financiado por el Ministerio de Ciencia, Innovación y Universidades con la referencia PGC2018-098699-B-I00. 
The analysis includes the identification of the generic features of the works, their spatial development to evaluate the preeminence and alternation of the urban or rural location, as well as the dramatic functionality of the interweaving of both worlds, from the integration of the characters of the urban setting in the rural one and vice-versa.

KeYwords: Urban comedy; Villainous comedy; Dramatic space; Feigned identities; Chronology; Socio-economic context; Literary tradition.

Si cortesana, tan bella; tan bella, si labradora, que de una suerte enamora y estoy muriendo por ella.

Al pasar del arroyo

L a caracterización de la comedia urbana tiene ya una larga tradición crítica en uno de los primeros trabajos específicos sobre este género, con la de enredo, de capa y espada o de costumbres contemporáneas (Menéndez Pelayo 1949:I,10), denominaciones que los estudiosos posteriores han seguido utilizando indistintamente, con ligeras precisiones (Arellano 1988:28 y 1996:37). ${ }^{1}$ En mi caso, me sumaré a esta sinonimia, aunque me resulta particularmente útil la calificación de «urbana» por la especial atención que quiero prestar al espacio de ficción.

Los rasgos característicos del género están bien delimitados y suelen partir de la célebre distinción de Bances Candamo entre "comedias de fábrica" y de "capa y espada". Estas últimas son «Aquellas cuyos personajes son solo caballeros particulares, como Don Juan y Don Diego, etcétera, y los lances se reducen a duelos, a celos, a esconderse el galán, a taparse la dama, y en fin a aquellos sucesos más caseros de un galanteo» (Theatro de los theatros, p. 33). Arellano [1988:38 y ss.] perfiló el género como «un tipo de comedia especial, de tema amoroso y ambiente coetáneo y urbano, con personajes particulares y basada fundamentalmente en el ingenio», en la que predomina un efecto de inverosimilitud logrado por la concentración temporal y espacial, así como por el uso extremo del azar y la acumulación de sucesos. Asimismo, es habitual, según

1. Arellano [1988:28, n. 3] prefiere desechar el término "de enredo" puesto que elimina la distinción con las palaciegas, palatinas o villanescas. 
señala el estudioso, la ruptura del decoro y la generalización de los agentes cómicos, que responden a la condición lúdica del subgénero, según la cual incluso el tema del honor tiene un tratamiento humorístico. Estas comedias vienen además identificadas por una inserción en la cotidianeidad, cercana al espectador, según las marcas geográficas (fundamentalmente urbanas), cronológicas y onomásticas.

En el caso de Lope de Vega, su condición de pionero y su extensa producción han permitido que existan además una serie de trabajos específicos sobre la forma en la que el Fénix materializó este subgénero. Desde los estudios de Wardropper [1974] y Weber de Kurlat [1976] se ha ido imponiendo la necesidad de contemplar el factor cronológico a la hora de perfilar con precisión las características de la comedia urbana lopesca. Así, Oleza [1981:166 y ss.], en su estudio sobre la propuesta del primer Lope, ya identificaba a los protagonistas de estas comedias urbanas tempranas como «damas y caballeros de medio pelo», cuya cotidianeidad y costumbres, ubicadas en ciudades concretas, se elevaban a aventuras, en las que se inclinaba «la balanza del lado del caso extraño y nunca visto, y del juego por el juego en que siempre se resuelve su elemento capital: el enredo». Señalaba además como conflicto más generalizado las dificultades para la realización amorosa de los protagonistas, vinculado a los problemas de honra, a los celos y al ocultamiento de identidad. Los amantes tendrán que legitimar su deseo a través del matrimonio y para ello utilizarán todo tipo de intrigas. Otro rasgo interesante señalado por Oleza es que el elenco de personajes está dominado por los galanes y las damas y solo en la comedia urbana madura aparecerán las historias paralelas y la comicidad centrada en un personaje tipificado.

Por su parte, Arellano [1996] ha resaltado como rasgos definitorios de las urbanas lopescas de primera época los siguientes: el lugar de la acción, que es sistemáticamente una ciudad española que se quiere fijar mediante referencias explícitas; la onomástica, aún no ajustada a la coetaneidad sino con cabida para nombres exóticos que pueden provenir de la comedia palatina o erudita; los protagonistas, galanes y damas antiheroicos y amorales, para quienes el honor y la honra son secundarios; la importancia del dinero en las relaciones y la estructura, excesivamente compleja, deshilvanada y laxa, con abundantes escenas costumbristas.

Por otro lado, la comedia villanesca áurea cuenta con el monumental estudio de Noël Salomon, articulado en torno a cuatro grandes categorías de villano: el cómico, el ejemplar y útil, el pintoresco y lírico y el digno. Esta clasificación puede dar 
muestra, por sí sola, de la versatilidad de un tipo dramático que está presente, según este especialista, en más de 200 obras lopescas (Salomon 1985:9).

A este trabajo se suma algún monográfico de especial interés como el resultante de la vigésimo cuarta edición de las Jornadas de Almagro, dedicadas a este género. Precisamente Felipe Pedraza, organizador de esta cita, resume los rasgos de estas comedias que podían resultar atractivos para el espectador del corral: «descripciones bucólicas, canciones y bailes populares, escenas de carácter costumbrista, tipos rústicos y graciosos, una fábula en defensa del amor puro y verdadero, una acción trágica en torno a la honra, la justicia poética en que los pequeños triunfan, tras mil padecimientos del poder injusto» (Pedraza 2002:8). Señala este mismo especialista a Peribáñez (1605-1608) $)^{2}$ como la primera muestra de un género al que pertenecen tres de las comedias áureas más leídas y estudiadas, como son Fuenteovejuna (¿1612-1614?), la calderoniana El alcalde de Zalamea y la mencionada.

Catalina Buezo [2002:297] afirma que «cabría aplicar la denominación de 'comedia villanesca' a una serie de obras dramáticas de nuestro teatro áureo en las que sobresale la figura del 'villano' como personaje literario». Sin embargo, antes de llegar a la plena conformación del llamado «género villanesco», lo rústico está presente en escena desde las primeras comedias de Lope, quien supo aprovechar el tirón del teatro del xvi e incluso anterior. Señala Salomon [1985:20-24] que ya desde época clásica se solían introducir sátiros y silenos para aligerar las tragedias, uso que pasó a las tablas medievales y posteriormente a los introitos, loas y pasos rústico-cómicos del xv o xvi. Lope solo tuvo que dar el salto de introducir estas piezas exentas en las comedias y los demás dramaturgos continuaron su estela.

Otra cuestión interesante es la confluencia de los géneros pastoril y rústico, que tienen fronteras comunes, pero mientras la primera «no se arraiga en la vida rústica real para idealizarla o poetizarla; arranca de un ideal sentimental al cual prados y bosques inconcretos proporcionan solo un marco», la segunda «no se niega a captar en la vida campestre elementos de la realidad por los que se interesa y a los que traspone estéticamente» (Salomón 1986:14). Señala Salomón que hacia 1600 el género rústico se impuso a la fórmula pastoril, que parecía agotada. No obstante, como ha señalado certeramente Antonucci [2013:151], «los límites de los ámbitos

2. Para fechar las obras, utilizamos la cronología de Morley y Bruerton [1968] o, en el caso de las comedias analizadas, las fechas propuestas por los editores críticos. 
semánticos a los que apuntan términos como "pastores", "labradores" y "villanos" no están siempre bien definidos: si muchas veces evocan un universo literaturizado o buscan al revés una verosimilitud de tipo embrionariamente sociológico, también es cierto que otras veces son, en cierta medida al menos, intercambiables». La confluencia va más allá de lo nominal y, utilizando un concepto más abarcador, que podría ser el "campesino" o "rural”, en oposición a "urbano", convivirán elementos, escenas y personajes procedentes de ambos mundos, como veremos. No obstante, el deslinde es importante, pues puede llevarnos a erróneas generalizaciones sobre lo 'villanesco' y su funcionalidad dramática si no diferenciamos ambas facetas.

En este terreno de la intersección de géneros, Pedraza afirma que los motivos villanescos «admitían sin dificultad la contaminación de otros géneros de éxito como la comedia de bandoleros o la comedia palatina» [2002:9]. Buezo [2002:314-315], en la conclusión de su tipología de lo villano en el teatro áureo, afirma que «sobre todo en los estadios iniciales y finales, las fronteras genéricas se difuminan y las excepciones se convierten en regla», por lo que «se puede hablar de comedias de enredo villanescas [...] que, en ámbito rústico, participan de muchas de las características de la comedia urbana de capa y espada». Por su parte, Arellano [1996:41] comenta que «la indeterminación genérica se percibe todavía en estas obras [urbanas tempranas que excepcionalmente salen de las fronteras nacionales], de manera análoga a algunas otras piezas en las que parte de la acción salta a un ambiente rural de aldea o sierra (La serrana de Tormes, El galán escarmentado) con tono y personajes propios de la comedia villanesca o de las farsas pastoriles». ${ }^{3}$

Existe, por tanto, un largo recorrido ya realizado por estos géneros de manera independiente y la evidencia de una hibridación, que merece ser estudiada. Para componer el elenco de obras que presentan esta hibridación genérica, hemos utilizado la base de datos de ARTELOPE (Oleza 2011-2021), que tiene la gran ventaja de admitir búsquedas a partir de identificadores de género primario y secundario. El resultado de introducir como término de búsqueda primario «comedias urbanas» y secundario «villanescas» fueron las comedias Los embustes de Celauro, La serrana de la Vera, La serrana de Tormes y Al pasar del arroyo. ${ }^{4}$ No hubo ningún resultado

3. Sobre la presencia de la hibridación en Lope, véanse también: Oleza [1997b:xv-xvi] y Resta [2020].

4. Se suprime El esclavo fingido, por ser de atribución dudosa. La selección, propiciada por la criba previa de ARTELOPE, pretende ser intensiva y no extensiva, para poder abordar los diferentes aspectos que influyen en la delimitación genérica. 
al invertir los términos. No obstante, completamos el listado con La villana de Getafe a partir del repaso, en la misma base de datos, de los términos de búsqueda «marco espacial» $\mathrm{y}$ «universo social» de las urbanas, puesto que son los dos elementos básicos que chocan en esta combinación genérica; aunque desde la primera lectura se revelaron también de interés otros como el de los orígenes e identidades ocultas, así como la evolución cronológica de las comedias. Sobre esta última cuestión, Antonucci [2013:155] ha señalado que «este tipo de comedias urbanas 'mezcladas' no son exclusivas de una fase temprana de la producción de Lope»; lo que corroboró la necesidad de incluir en el estudio esta última obra, cercana en la fecha de redacción a $A l$ pasar del arroyo, y perteneciente a una etapa diferente a la de las tres primeras, todas ellas anteriores a $1600 .^{5}$

La estructura del análisis incluirá la identificación de los rasgos genéricos de la comedia, el desarrollo espacial de la misma — para sopesar la preeminencia y alternancia de la ubicación urbana o rural-y la intersección de ambos mundos, valorando la función de las incursiones de los personajes de la órbita urbana en la rural y viceversa, y su imbricación en la intriga.

La serrana de Tormes,${ }^{6}$ fechada entre 1593 y 1594, tiene los rasgos de una comedia temprana de Lope: elenco numeroso de personajes; ausencia de una doble acción; participación de personajes secundarios poco vinculados a la acción principal, entre los que se reparte la comicidad a falta de un gracioso bien definido; cierta inconsistencia de los protagonistas, que presentan un carácter apicarado, especialmente Alejandro, el galán; ambiente tabernario con la presencia de soldados, estudiantes y prostitutas; lances fatales que desembocan en la muerte de algún personaje; y lo que nos interesa especialmente en este momento, una variedad de espacios de ficción, con frecuentes y bruscos -implican vacío de escenario- cambios de ubicación. A ello habría que sumar los travestismos y variaciones de identidad, nada sorprendentes por su presencia en cualquier época de la producción lopesca, si no fuera porque en esta obra más que uso se hace abuso de este motivo. ${ }^{7}$

5. No hay que olvidar que a finales de la primera década del xvir y al comienzo de la segunda verán la luz las tres grandes obras de ambientación villana del Fénix: Peribáñez (1605-1608), El villano en su rincón (1611) Fuenteovejuna (¿1612-1614?).

6. En todas las obras hemos seguido las ediciones de Prolope. En este caso la de Eugenio Maggi [2017:135-288].

7. Diana, la dama, asume la personalidad de don Martín, soldado, para marcharse de casa; de Dominga de Tormes, villana, para refugiarse entre los carboneros y se disfraza de estudiante para seguir al galán. 
El primer acto podría responder a la distribución espacial de una comedia urbana, en la que se alternan los espacios exteriores (calle), con alguna incursión extramuros (afueras de Toledo) propia de las obras de primera época, e interiores (casa de la dama y del galán). ${ }^{8}$ Los lances amorosos entre hidalgos, con presencia de cartas, retratos, duelos e intervención de los viejos (tío de la dama y padre del galán) de esta jornada se corresponden también con las características del género. ${ }^{9}$ Sin embargo, la huida de la dama nos traslada en el segundo acto a las sierras de Castilla, con estancias intermitentes entre el espacio villano y Salamanca, que se alternarán a lo largo de toda la segunda y tercera jornadas, aunque porcentualmente predomine el espacio urbano.

En cuanto a la intersección de ambos mundos, los villanos hacen una sola incursión en la ciudad, en cuyo bullicio se ven avasallados por los estudiantes, que los insultan y menosprecian (vv. 2068-2081, 2565-2576, etc.): ${ }^{10}$ mientras que lo urbano, personificado en Diana, Alejandro y su cuadrilla de amigos estudiantes, provocará graves perjuicios en la aldea. Desde el momento de la acogida de Diana, que se esconde entre ellos asumiendo la identidad fingida de una villana, Dominga de Tormes, las relaciones de la comunidad se alteran. El amor manifestado por Elenco, uno de los carboneros, es utilizado por Lope para introducir pasajes jocosos, en los que se resalta su necedad, como aquel en que animaliza y rebaja a la dama al hablar de su fertilidad:

$\begin{array}{ll}\text { Elenco } & \text { En nueve meses, Chamizo, } \\ & \text { tres veces ha de parir. } \\ \text { CHAMizo } & \text { ¿A tres meses? ¿Tú no ves } \\ & \text { que a lo natural repugna? } \\ \text { Elenco } & \text { ¿Cualquiera se pare una, } \\ & \text { par Dios, que ha de parir tres! } \\ & \text { Vuestra burra, ¿cuánto estuvo } \\ & \text { preñada de mi rocín?, } \\ & \text { que la burra de Martín } \\ & \text { más poco termeño tuvo... }\end{array}$

(vv. 1511-1520)

8. Para el valor simbólico de esta alternancia, véase Arata [2002]. Por otro lado, para el estudio del espacio rural, que no villanesco, frente al urbano en las comedias tempranas de Lope, véase Escudero [2001].

9. Así lo afirma también Eugenio Maggi [2017:135-136], editor de la obra.

10. Maggi [2017:141] señala la vinculación de este pasaje y otros similares con el Auto del Repelón, atribuido a Juan del Encina. 
En este contexto, ni el público ni Diana pueden tomarle en serio y la dama se dedica a esquivarlo, pero sin rechazarlo completamente para poder utilizarlo de nuevo al final de la obra, cuando su vuelta al pueblo provoque un desenlace fatal para Elenco, que muere a manos del galán. Parece como si el planteamiento de ambos espacios estuviera confrontándolos en términos de barbarie y civilización: el villanesco es risible por su tosquedad e ingenuidad y sale peor parado, aunque es el más honesto de los dos mundos. Lope se regodea sacando partido al primitivismo de estas gentes aldeanas para generar comicidad en varias escenas, insertadas a modo de pasos o entremeses que muestran una estructura laxa e inmadura (Arellano 1996:57), como la citada anteriormente o aquella en la que, en la búsqueda de un castigo para el homicida, el campesino que se erige en autoridad legal propone una sentencia tan absurda que provoca la risa del propio reo:

Chamizo Mando pues que sea ahorcado

por lo pies y asaeteado,

y aun era de parecer

que no le den de comer

hasta después de finado. [...]

Y mando que por sus daños

cuelguen tripas y redaños

de una escarpia en algún cesto,

y que vaya después desto

a galeras por diez años. [...]

AlejANDRo ¡Por Dios, bueno quedo ansí!

Con estar tan lastimado,

a risa me ha provocado. (vv. 2878-2899)

El planteamiento no es, por tanto, benevolente para con lo villano, que se inserta aquí para ofrecer un tipismo cómico cercano al teatro del xvI, reflejando las características amables y tópicas de este estrato social (hospitalidad, sinceridad, llaneza), pero utilizándolo sobre todo como elemento cómico del que reírse por su extremada simpleza y como cabeza de turco de los enredos amorosos de los hidalgos. Aunque la dama mencione el tópico de la alabanza de aldea («Madre, vámonos de aquí / que estoy ya desesperada. / ¡Oh, ciudad triste y cansada, / Nunca yo viniera a ti! / Mejor me estaré en la sierra», vv. 1947-1949) lo hace por despecho y sin convicción, pues no tendrá reparos en participar en el engaño final. Ni siquiera la 
sensatez de Batavo, el carbonero viejo que ha actuado como padre de Diana-Dominga, evitando el linchamiento del hidalgo, será recompensada en el desenlace: los estudiantes, amigos de Alejandro y la propia dama, burlarán a los aldeanos con un simple truco de disfraces — que los villanos interpretarán como brujería—, ${ }^{11}$ liberarán al homicida y les esquilmarán bajo la amenaza de un castigo. Incluso en el lance último, cuando el padre del galán y el tío de la dama se presentan buscándola, Diana y Alejandro se saldrán con la suya mintiendo y culpabilizando a los serranos:

AlejANDRO

Preso estando

por la muerte de un labrador

que a Diana vi forzando,

en este traje, señor,

Diana me libró. ～(vv. 3164-3168)

Los protagonistas urbanos, por su parte, con más estatus, más formación y más malicia, se aprovechan de su hospitalidad y los utilizan, a pesar de lo cual obtienen la recompensa del matrimonio. Ni siquiera la muerte de un aldeano inclina la balanza hacia lo serio, como si ese daño colateral no fuera suficiente a ojos del dramaturgo o del público para modificar las expectativas genéricas confirmadas en este desenlace feliz y asentadas en el mantenimiento de la honra por parte de la dama, en el retrato desenfadado de la vida estudiantil y en el tono cómico que preside la mayor parte de la obra.

El espacio rural y lo villano han aportado un contexto colorista por donde derivar un enredo, cuyos protagonistas siguen perteneciendo en todo momento al mundo urbano, sin que exista una verdadera imbricación dramática ni argumental y menos aún una visión bucólica o una defensa del campo.

De una fecha cercana a la obra anterior es La serrana de la Vera ${ }^{12}$ que Morley y Bruerton [1968:222-223] sitúan en torno a 1595-1598. Al igual que aquella, la comedia arranca con un primer acto que corresponde tanto espacial como argumentalmente a una comedia de capa y espada de la primera época, pero menos apicarada: un enredo amoroso a tres bandas, basado en la acumulación de malentendidos,

11. La vinculación de los estudiantes salmantinos y la magia proviene de la leyenda de la cueva de Salamanca, que arraigó con fuerza en la literatura del Siglo de Oro. Para un estudio de este motivo en Lope, véase Magnaghi [2014:163-174].

12. Hemos utilizado la ed. de Lola González [2008:1393-1519]. 
en el que se ven involucradas tres parejas, además del personaje que detenta la autoridad familiar, don Luis, hermano de la protagonista, y Fulgencio, el galán suelto que la pretende y ha urdido todo el engaño. Respetando el juego simbólico de los exteriores e interiores, los lances tienen lugar entre la calle, espacio reservado para los diálogos de los galanes, y la casa de la dama, a la que se traslada el intercambio de reproches una vez que el conflicto ha estallado. Hay que añadir un cuadro extramuros, a las afueras de Plasencia (coincidiendo también en esto con La serrana de Tormes), en la Vera, donde Leonarda se disfraza por primera vez de serrana, augurando la transformación más profunda que se producirá al inicio del segundo acto. A mitad de este (v. 1652), la acción se traslada al monte y allí se desarrollará por completo el resto de la obra, con alguna incursión en una aldea. ${ }^{13}$

Las similitudes con la comedia anterior no son solo espaciales, sino también argumentales, en lo que se refiere a la adopción de un estatus inferior por parte de la protagonista. Sin embargo, el rol que asume abre una perspectiva diferente, ya que Leonarda no se integra en una comunidad rural sino que adopta el papel de serrana, conectando con una doble tradición literaria, tal como explica González [2008:1398 y ss.]: la de la lírica popular de transmisión oral, que retrata a la mujer marimacho que se lanza a los caminos para asaltar a los hombres, pero principalmente la de la virgo bellatrix, una «nueva amazona cortesana» tomada de la tradición caballeresca, que inauguró una serie de obras barrocas que recreaban el motivo de la mujer bandolera. No obstante, por lo que respecta a la intersección del mundo rural y urbano, nos interesa destacar el comentario de la editora, quien interpreta que Lope se distanció de la tradición popular por un nuevo interés que consistía en «trasladar la rebeldía de las mujeres del pueblo, recogida por la leyenda y los romances, a un estamento superior, el de la nobleza urbana» (González 2008:402).

No existe en este caso una alternancia de espacios urbano-rústico, sino que la intersección de ambos mundos se produce, según lo anterior, de mano de la protagonista y, de nuevo, a través de la asunción de una identidad ficticia y de su traslado al monte. Sin embargo, el contacto con lo villano llega cuando la serrana, haciendo gala de la condición «caballeresca», y en su afán vengativo contra los hombres, acude a la aldea en ayuda de una villana que ha quedado embarazada de otro campe-

13. Existen dos escenas, en las que participan don García y don Rodrigo (vv. 2381-2411) y Estela y Teodora (vv. 2744-2765) respectivamente, en las que resulta difícil determinar la ubicación precisa. La mención en ambos casos de «la casería», parece indicar que se encuentran cerca de la aldea. 
sino, quien no quiere cumplir su palabra de matrimonio. Sin embargo, no deja de ser significativo que el desenlace de esta incursión de la serrana «urbana» en la aldea culmine cuando ella dé muerte a un aldeano que intentaba capturarla. No será este el único damnificado en escena, sino que también matará a un buhonero y estará a punto de quitarle la vida a otro campesino. En su afán revanchista, causado por el despecho al sentirse engañada por don Carlos, su prometido, y coaccionada por su hermano, sus víctimas identificables serán hombres del pueblo, ya que a don Juan le perdonará la vida y salvará la de su hermano. No obstante, estas muertes, que parecen inclinar la obra hacia el drama serio, en el caso de esta versión lopesca —no así en la de Vélez de Guevara—, ${ }^{14}$ no impiden un desenlace feliz, con la salvación de la serrana noble y la restauración de todas las parejas. Se diluye, por tanto, el riesgo trágico, si es que alguna vez ha existido.

$\mathrm{Al}$ igual que en la serrana de Tormes, los villanos son colaboradores necesarios para desarrollar una trama, que presenta flecos y lagunas, presidida por los conflictos y enfrentamientos derivados de lances de amor y honor entre hidalgos, ajustados a la principal característica de las comedias urbanas, aunque esta urbe sea una pequeña población extremeña: Plasencia. La incursión en el mundo villanesco de los personajes hidalgos es testimonial, como lo es la presencia de los aldeanos — caracterizados casi en exclusiva por su lenguaje (véanse los vv. 2301-2381) —, mientras que el desarrollo en la sierra de una buena parte de la acción aporta el contexto ambiental y legendario, útil para que la dama disfrute de un estatus que le dé temporalmente más libertad, y más verosimilitud dramática a su comportamiento y deseo de venganza. De igual forma, la actitud de don Carlos, que también se lanza al monte a vivir como un salvaje -incluso privado del habla por una promesa - para seguir a Leonarda y penar su rechazo, se sitúa en la misma órbita de lo novelesco o legendario.

La descripción del espacio natural tiene ecos pastoriles, en algunos pasajes en los que la serrana pone por testigo de sus lamentos a los elementos que la rodean («Claro cielo, sol hermoso, / agua, viento, fuego y tierra, / verdes enebros armados, [...] de mis lastimosas quejas / ecos», vv. 1744-1750), y rústicos, en alusiones a la utilería (Leonarda: «Dame, Avendaño, la espada / Cuchillo de monte había. / Leo-

14. Este autor escribió una comedia homónima posterior, basándose en la misma tradición romancística, de la que Lope de Vega se aleja al no incorporar «la condición sensual de las serranas medievales» (González 2008:1399). Por su parte Vélez de Guevara se mantiene más fiel a las fuentes y lleva su obra hacia un final trágico que concluye con la muerte de la protagonista. 
narda: No es, Avendaño, este día / para guarnición dorada, ni de cuchillo de monte», vv. 1113-1117) y al vestuario en las acotaciones («Sale Leonarda, con capote de dos baldas y faldón de pellejo de tigre y montera de lo mismo, zapato y polaina, espada de tabali y arcabuz», v. 2056Acot), pero no hay verdadera imbricación argumental de lo villano en la trama ni rastro del tópico de alabanza de aldea. Por otra parte, los lances de espadas que se desarrollan al final del tercer acto podrían tener lugar igualmente en la calle de cualquier núcleo urbano.

Casi coetánea de las anteriores, perteneciente aún al primer Lope, es la comedia Los embustes de Celauro, ${ }^{15}$ fechada en 1600 . Tenemos en este caso una obra ubicada en un espacio de ficción alejado del contexto español, el Piamonte, pero que se concreta en unos espacios de representación que no distan demasiado de los vistos en las dos obras anteriores. El primer y segundo actos se desarrollan en una alternancia entre interior y exterior de la casa de la dama o de los dos galanes. Será en el tercer acto donde la acción se desplace a un bosque y a una casa de campo, propiedad del barba, el padre del galán.

Los lances que se suceden corresponden a los habituales juegos de amor y celos, propios de comedias de enredo primerizas: Lupercio duda de la fidelidad de Fulgencia, a causa de las intrigas de un segundo galán, Celauro, que la desea y no duda en meter en lid a Leonela, su propia hermana, arruinando la relación de esta con Otavio, para conseguir sus fines. No obstante, existen dos elementos que distorsionan la pertenencia sin matices a este género, como son el personaje de Celauro, muy similar a Fulgencio en La serrana de la Vera, galanes intrigantes y maquiavélicos propios de las comedias tempranas, y el hecho de que la pareja protagonista esté casada y tenga dos hijos, lo que incorpora un nuevo motivo genérico acercándola a los dramas de honor conyugal. Este último aspecto hace que planee a lo largo de toda la obra un cierto riesgo trágico que se manifiesta en las peticiones de varios personajes (Fulgencia a Lupercio; Lupercio a su padre; Celauro a Lupercio) de ser castigados con la muerte, amagos de suicidio (de Lupercio), violencia de género (de Celauro a Fulgencia), violencia doméstica (niños arrancados de los brazos de su madre y sometidos a penalidades), linchamientos frustrados, etc. No obstante, el desenlace feliz y la falta de una intención ejemplarizante clara la llevan de vuelta a la órbita de la comedia, aunque de la comedia seria.

15. Hemos utilizado la ed. de Marco Presotto [2002:1221-1350]. 
El universo villano hace su aparición en la tercera jornada, ya que hasta ese momento es difícil ubicar la procedencia de Lupercio, quien fue visitado por su progenitor al inicio de la obra, pero sin hacer referencias a su origen. Es al comienzo de la tercera jornada cuando sabemos que el galán es hijo de un labrador rico que le ha permitido, y financiado, vivir en la ciudad, aunque se arrepiente de ello:

\begin{tabular}{|c|c|}
\hline GERARDO & $\begin{array}{l}\text { No hija; en la villa fue, } \\
\text { adonde yo le embarqué } \\
\text { para perderle en la mar. } \\
\text { Que si aquí en aquesta sierra } \\
\text { adonde yo le he crïado, } \\
\text { le hubiera siempre guardado, } \\
\text { menos peligros encierra. }\end{array}$ \\
\hline
\end{tabular}

La alusión al "mar" proceloso de la urbe que habría corrompido al joven villano parece llevarnos al tópico del desprecio de corte y alabanza de aldea. No obstante, a estas alturas de la obra ya sabemos que Lupercio está perfectamente integrado en el ambiente urbano, lleva diez años casado con una dama «de buen origen, pero pobre» y su relación, desde su inicio, ha estado basada en el amor y no en el engaño femenino u otras tretas de damas urbanas de "medio pelo". De hecho, es el propio galán el que está falseando la realidad para seguir manteniendo la subvención paterna, y el conflicto dramático está provocado por Celauro, otro galán de la baja nobleza urbana, quien tampoco se mueve por un deseo materialista de desplumar al incauto sino por celos y amor. Por lo tanto, no existe una intención ejemplarizante de mostrar los peligros de la corte, más allá de este comentario del barba, ni siquiera de confrontar las dos formas de vida.

Puesto que Lupercio se comporta como un galán urbano a todos los efectos, no hay incursión de lo villano en la ciudad, mientras que el recorrido contrario nos conduce, como en las obras anteriores, a la utilización de los espacios extramuros como refugio y vía de escape para los hidalgos en apuros. Se produce la habitual transformación de la dama en aldeana, con un travestismo explícito con repercusiones en la trama - pues el paso de su traje noble a manos de los campesinos provocará varios lances de la acción- y la asunción de un nuevo nombre, Tebandra. El villano rico la integra sin dificultad en su casa y pronto le propondrá matrimonio, sin que ello contravenga las normas morales, pues, aunque ella ya está casada con 
su hijo, él no sabe quién es. Curiosamente, el conflicto social que podría derivarse de que una dama se case con un villano queda diluido desde el inicio, puesto que ya sucedió diez años antes del comienzo de la acción y ha quedado corroborada la pertenencia tácita de Lupercio a la órbita urbana. El galán sale de la ciudad huyendo de la supuesta afrenta al honor que ha cometido su mujer para no matarla y el azar dramático hace que retorne, cual hijo pródigo, a casa de su padre. Este acepta las disculpas y restituye el orden y honor familiar dando muestras de magnanimidad, pero sin vincularlas a su condición villana.

Solo unas cuantas escenas muestran los anhelos cotidianos de los auténticos villanos, como el del que lleva el significativo nombre de Belardo, quien quiere proporcionarle a su futura esposa el mejor traje, a lo que su padre le responde con una reflexión moral:

$\begin{array}{cl}\text { BELARDo } & \text { En vuestro tiempo era bien } \\ & \text { vestir las novias de paño; } \\ & \text { Sabed, padre, que este año } \\ & \text { se muda el paño también. } \\ \text { FELicio } & \text { Pues bien haces si le mudas, } \\ \text { que, al tiempo que yo gozaba, } \\ \text { la virtud vestida andaba } \\ \text { y las personas desnudas. } \\ \text { Ahora, por la inquietud } \\ \text { con que se alteran las vidas, } \\ \text { van las personas vestidas } \\ \text { y desnuda la virtud. (vv. 2164-2175) }\end{array}$

No obstante, se trata de una apreciación que no tiene mucho desarrollo posterior, más allá de mostrar la autenticidad en estas gentes que lleva a Belardo a pedir ayuda a sus paisanos para perseguir a quien le ha quitado el traje que ha intercambiado con Fulgencia. Este lance hará que castiguen sin piedad, en vez de a Fulgencio, a Celauro, al que dejan atado a un árbol para que le devoren las fieras, aplicando, sin saberlo, justicia contra el causante de todo el enredo. Pero no creemos que haya intención en el autor al hacer que la pena llegue de manos de los aldeanos sino simple azar dramático, para provocar que se lo encuentre Fulgencio y consiga su expiación confesándole su responsabilidad en los males que le ha causado. $\mathrm{Ni}$ si- 
quiera puede considerarse que la intervención final de Gerardo, el padre del galán, como deus ex machina, contextualizada en su hacienda rural, tenga un valor reivindicativo hacia lo villanesco. A pesar de que la presencia del tópico de la alabanza de aldea es mayor en esta obra que en las anteriores, aún faltan unos años para esto.

Por tanto, en la obra tienen un peso importante las características de la comedia urbana - amor, celos, baja nobleza, coetaneidad, inverosimilitud por acumulación de sucesos, onomástica-, que se completa con algunos rasgos de estas obras en su primera fase - falta de trama secundaria y agente cómico, cierta amoralidad en el protagonista, presencia del dinero, extensión a Italia y al contexto rural- y con la indefinición genérica, no solo por lo villanesco sino por la presencia del riesgo trágico y el drama conyugal. El espacio rural posibilita la huida de los protagonistas, pero no deriva hacia el conflicto social que podía suponer un emparejamiento desigual, mientras que el tópico de menosprecio de corte y alabanza de aldea, aunque está presente, no se desarrolla ni tiene trascendencia en la trama. La imbricación de ambos mundos es funcional, pero superficial y deslavazada como la estructura en sí.

Con La villana de Getafe (1610-14), ${ }^{16}$ el avance cronológico respecto a las comedias anteriores lleva aparejado un salto cualitativo que pone de manifiesto una evidente evolución en la conformación de la comedia lopesca en general, ${ }^{17}$ y en el género villanesco en particular. Oleza [1997b:xi y ss.] vincula el cambio de etapa a aspectos biográficos que sitúan a Lope entregado a la vida familiar (matrimonio con Juana de Guardo y convivencia con Micaela de Luján) y alejado moralmente de la corte en el periodo que media entre 1598 y 1614 . Su condición de pequeño propietario, tras la compra de su casa en la calle de Francos, y de profesional que vive de su trabajo podrían haber generado empatía para con los labradores acomodados que reivindican su dignidad. No es de extrañar, por tanto, que a este periodo pertenezcan las tres grandes obras de ambientación villana del Fénix, Peribáñez (1605-1608), El villano en su rincón (1611), Fuenteovejuna (¿16121614?), y la que ahora nos ocupa.

En esta comedia, la imbricación del componente villano con el urbano se produce argumentalmente de manera efectiva, con una intersección de ambos mundos

16. Hemos utilizado la ed. de Adelaida Cortijo y Elisabeth Treviño Salazar [2015:241-414].

17. Sobre los límites de las diferentes etapas de la producción lopesca, véase Shergold [1967], Rozas [1976 y 1990] y Oleza [1997a, 1997b y 2003]. 
que conduce a un desenlace aparentemente sorprendente, el matrimonio entre el noble y la villana. ${ }^{18}$

El funcionamiento del espacio en esta comedia también varía respecto a las anteriores: ya no vamos a encontrar ningún cuadro ubicado en un entorno exterior no habitado (la sierra, el monte, «casares derribados», etc.), sino que responde a una alternancia de interiores y aledaños de las casas de don Félix, el galán, de doña Ana la dama madrileña, y de Inés, la villana. En este último caso, son cuatro los cuadros que se ubican en el pueblo de Getafe, tres en el primer acto y uno al inicio del segundo. De ellos, el primero incluye una escena de ambientación villanesca y folklórica, pero los otros tres, que tienen lugar en la tapia de la casa de Inés y en las calles del pueblo, posibilitan el encuentro de la villana con don Félix o con Hernando, el aldeano que la pretende. ${ }^{19}$ Por lo tanto, la función de estos espacios es idéntica a la que podría desarrollarse en una calle de Madrid, o de cualquier otra ciudad: responde a la habitual alternancia de interiores y exteriores y ha eliminado otros espacios externos, como corresponde a la comedia de capa y espada consolidada.

La intersección de ambos mundos se consuma con el matrimonio y cambio de estatus de la villana, pero también gracias a la inmersión espacial previa que contemplamos a lo largo de toda la comedia y que se deja ver en el número de cuadros en los que hay una presencia de personajes ajenos a ese ámbito y en los antecedentes narrados por los personajes, que conforman un escenario verbal en diferido. Sin ir más lejos, en el segundo cuadro, Inés sitúa el primer contacto con el galán, en Madrid, ante la iglesia de San Sebastián, «el santo flechado» (vv. 209-281) ${ }^{20}$ La presencia de los personajes villanos en Madrid, en casa del galán y la dama, se producirá en cuatro de las siete ubicaciones de la segunda jornada y en la totalidad de las de la tercera; mientras que don Félix está físicamente en Getafe, en todos los cuadros que allí se desarrollan. Sin duda, la inmersión de Inés en el ambiente urbano es más significativa por lo que a la evolución del enredo respecta, ya que todos los

18. Este último aspecto, así como el personaje de Inés, la villana, ha sido objeto de atención por parte de la crítica. Véase Díez Borque [1998a, 1998b y 2002], Campbell [2000] y Ketan Mehta [2011].

19. Para profundizar en el juego con el espacio, en especial con la escena de la tapia, véase Couderc [2005].

20. La alusión a la construcción de la torre de la iglesia ha servido además para intentar precisar la fecha de redacción. Véase Díez Borque (en su edición de La villana de Getafe, p. 54) y Cortijo y Treviño [2015:241]. 
personajes bailarán al son que marquen sus engaños, pero la presencia de don Félix en el entorno de la villana, con bordado y escena folklórica incluida, aportan un cuadro contextualizador de la vida rural, pero también un espacio de representación del que el noble participa. En una concepción más simbólica que de imitación de la escena áurea (Rubiera 2005:28), y en la que el recurso de las narraciones anticipadoras o retroactivas (Rubiera 2005:38) estaba ya ampliamente testado, si Lope sumerge al protagonista en el ambiente rural es porque quiere que el público disfrute de la habitual variedad de escenarios de la comedia nueva, pero también busca que el espectador vea con sus propios ojos la persecución del galán a la villana, que justificará su suerte final.

La concentración espacial se ve acompañada, por tanto, de una estructura de la trama mejor construida que en las obras anteriores. Los lances no parecen sucederse de manera desordenada y acumulativa, como en las comedias comentadas, sino que, en los sorprendentes virajes de la acción, que llevan al límite la verosimilitud (parada casual de don Félix en Getafe, frente a la casa de Inés; encuentro de Lope con doña Ana en su breve retorno a Madrid; llegada de la carta del verdadero don Juan en pleno desenlace, etc.) como es preceptivo en el género, se deja ver un plan preconcebido, en el que la intersección de lo villano y lo urbano juegan un papel argumental y simbólico.

De igual forma, el motivo de la asunción de identidades falsas sigue siendo una constante, aunque en esta ocasión, en sintonía con lo anterior, las dos transformaciones de la protagonista (en criada primero y en galán después) contribuyan de forma eficaz a compactar la trama y no a dispersarla, como sucedía en La serrana de Tormes, por ejemplo. Fijémonos en la primera de las mutaciones: Inés, la villana, se convierte en Gila para entrar al servicio de la dama que se va a casar con su galán, y así poder seguir entorpeciendo el enlace. De manera simultánea, Hernando, el villano al que ella rechaza, se convierte en cochero del galán para seguirle la pista. Este cambio de roles se produce, por tanto, sin una alteración del estatus social, tal como se deja ver en el nuevo nombre que adopta Inés que, en todo caso, rebaja un poco más su condición para ajustarse a la imagen de la sirvienta boba, que incluso hace reír con sus ocurrencias. ${ }^{21}$ Para esta villana tracista, decidida e inteli-

21. Es significativa la elección de los nombres de la comedia: de las 77 apariciones del nombre de Inés que recogen Morley y Tyler, en su obra Los nombres de personajes en las comedias de Lope de Vega [1961:229-231], 24 son damas y el resto son villanas o criadas. En cambio, el nombre de Gila es 
gente, que está a la altura de las damas de la comedia madura, se adapta el lenguaje y la métrica a lo rústico, como en este romancillo inicial, donde se percibe incluso un cierto orgullo de clase:

INÉS

Pellizcome;

y a lo que me dijo

respondile ¡oxte!,

como acá lo dicen

nuestros labradores.

(vv. 282-286)

O a lo cómico, para hacer más creíble su condición de criada simple y risible:

INÉS [...] ¿No habrá visto por acá

el jumento que perdí?

DoÑa Ana No, hermana.

INÉS ¿No ha entrado aquí?

Pues diz que ha llegado ya.

Doña Ana Ved lo que en el mundo pasa.

INÉS Era un pollino andaluz

que era de estos ojos luz

y el espejo de mi casa.

DoÑa ANA ¡Qué extraña simplicidad! [...]

Si quieres ser mi crïada,

casa es esta que profesa

remediar los que lo son.

InÉS ¡Pardiez!, por ver si al pollino

puedo hablar, me determino.

DoÑa ANA (Desta simple condición

se han de tener las crïadas).

(vv. 1383-1415)

Pero hay que contar con la connivencia de un público, que identifica al jumento del que habla con don Félix, en un ejercicio de rebajamiento del noble al que aspira como marido. Este pasaje se suma a todos los que hacen del ascenso social uno

asignado en nueve ocasiones y siempre para personajes de villana o de criada (Morley y Bruerton 1961:228). Por su parte, el nombre de Hernando lo incluye en la lista de los que solo pertenecen a caballeros excepcionalmente, cuando corresponden a personajes históricos (Morley y Bruerton 1961:22). 
de los motivos centrales de la trama. Lope se ha preocupado de dejar el rastro del conflicto social (la villana Pascuala ha intentado disuadirla del matrimonio desigual, la propia Inés ha admitido su inferioridad ante don Félix, etc.), pero también de su posible solución, que no resulta contraria al planteamiento dramático o ideológico:

$\begin{array}{ll}\text { Don FélIX } & \text { [...] sabed que aquesta señora } \\ & \text { no es Gila, que son disfraces } \\ & \text { con que su paciencia supo } \\ \text { obligarme y conquistarme. } & \text { Es hija de un hombre hidalgo } \\ \text { de Getafe, a quien le trae } & \text { don Juan cuarenta mil pesos } \\ \text { de dote con que se case }\end{array}$ (vv. 3349-3356)

La hidalguía posibilitará la restauración del orden, y los engaños persistentes de Inés surtirán efecto, premiando su honestidad ( no me puedo arrepentir / de haber guardado el decoro / como le debo a mi honor», vv. 1158-1160), inteligencia y amor constante, al tiempo que castigarán la ambición y veleidades del galán:

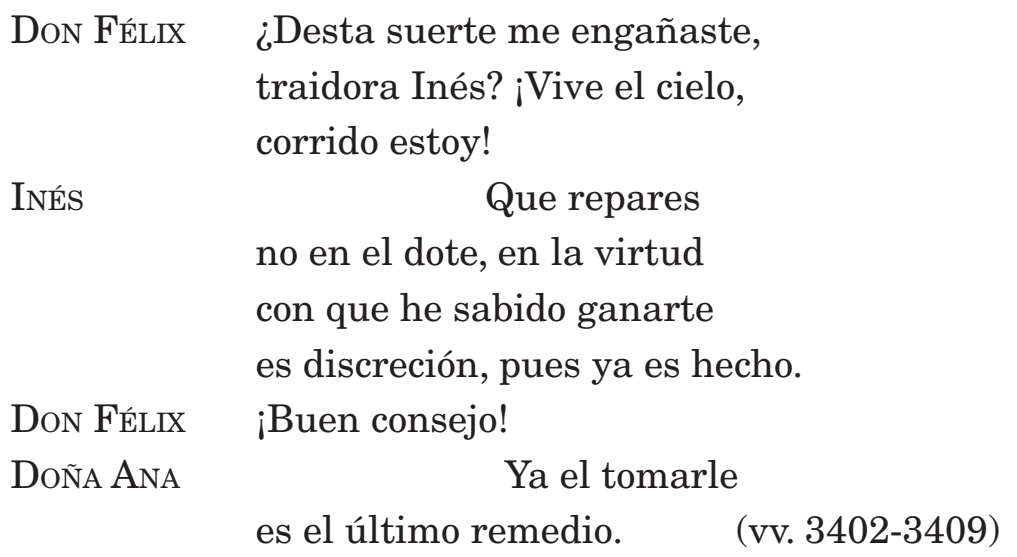

La justicia poética que encumbra a la villana es aplicada por un Lope que por estas fechas ha visto triunfar al menos su Peribáñez, si no sus tres grandes comedias villanescas, y se suma a toda una corriente de dignificación villana. Tal como explica Salomon [1985:177 y ss.], después de 1600 el vínculo de la alabanza de aldea con los problemas económicos derivados de la crisis del campo genera toda una lite- 
ratura «fisiocrática» y religiosa que ensalza la vida en el campo. Lope, que ya había participado activamente en la canonización de San Isidro, se suma a las nuevas directrices político-culturales que orientaban también el gusto del público para ensalzar a esta protagonista por encima de las habilidades cortesanas:

DoÑa ANA

¡Que engañe

una ruda sayaguesa

hombre que suele alabarse

que en la corte no hay ingenio

que con el suyo se iguale!

(vv. 3316-3320)

A pesar de la evolución que comentamos respecto a las tres comedias anteriores en cuanto a la mejor imbricación argumental y espacial de lo villano, existen una serie de elementos que muestran claramente su pertenencia a la comedia urbana: la explotación del azar; la preeminencia del ingenio de la protagonista, cuyos engaños provocan constantes escenas de flirteo, celos, desengaños y lances de espadas; el conflicto principal que implica el choque entre honra y deseo, apoyado en el juego simbólico de exterior interior, aunque con un tratamiento relajado del honor y el estatus social, que implica una cierta ruptura del decoro. No obstante, la importancia que adquiere el motivo del ascenso social de la protagonista, la asunción de un segundo estatus bajo de la villana, respaldado por las variaciones lingüísticas, que le permite el acceso a la casa de la dama rival noble, y la aparición de cuadros rurales de los que se hace participar a los caballeros son muestras de una imbricación más coherente y estructurada de lo villano, que en las obras anteriores. Pero la mayor muestra de hibridación es, sin duda, el desenlace que se materializa con una estrategia similar a la de El perro del hortelano, comedia inscrita generalmente en el género palaciego, pero para la que Antonucci [2004] propuso, significativamente, una interpretación en clave urbana.

Al pasar del arroyo es una comedia de $1616,{ }^{22}$ cuando el género de capa y espada ya estaba plenamente conformado y se había producido una sustancial reducción de espacios de ficción, aunque podían mantenerse un abundante número de alternancias espaciales, como hemos visto en La villana de Getafe. A diferencia de esta, Al pasar del arroyo sí presenta ubicaciones extramuros, de tránsito entre Ma-

22. Hemos utilizado la ed. de Beatriz Zanusso y José Enrique Laplana Gil [2013:649-802]. 
drid y el cercano pueblo de Barajas, lo que por sí mismo resulta un primer indicio de que no nos encontramos ante una obra exclusivamente urbana y parece retroceder a las obras primerizas del Fénix. No obstante, es fundamental tener en cuenta que Lope quiso materializar ante los espectadores el espacio que recoge la fuente folklórica, origen del título y del suceso desencadenante del conflicto amoroso: «Al pasar el arroyo / del Alamillo, / las memorias del alma / se me han perdido» (vv. 2882-2885); aunque el dramaturgo añadiera el arroyo de Brañigales, más próximo a Madrid y famoso por sus peligrosas crecidas. ${ }^{23}$ Resulta, por tanto, imprescindible contemplar la funcionalidad que tiene la introducción de estas alteraciones espaciales sobre la construcción del subgénero híbrido, así como aquellos otros motivos temáticos recurrentes, como es una vez más el de las identidades ocultas, en este caso no fingidas sino resultado de la revelación de un origen nobiliario de los villanos protagonistas, más abundantes en el género palatino o novelesco, pero que provocan, una vez más, la variación repentina del estatus social.

Para no perder nuestro hilo conductor, el espacial, resulta de interés comprobar que, de nuevo, en esta obra Lope ve la necesidad de ubicar a los personajes en ambos contextos, el villano de partida y el cortesano recuperado, en lugar de optar por soluciones más simples que podrían pasar por un relato verbal de los antecedentes o de los sucesos fuera de escena, también utilizado con especial fruición en esta comedia.

A través de las didascalias implícitas es posible conocer las distintas ubicaciones e incluso el itinerario de los personajes, aunque con algunas imprecisiones. Los dos primeros actos se desarrollan casi por completo en Barajas o aledaños, mientras que la tercera jornada tiene lugar íntegramente en Madrid, en casa de don Luis y su hermana Lisarda, ambos implicados en el conflicto amoroso. Cuantitativamente, la balanza se inclina hacia el espacio rural, sin embargo, la intersección de ambos mundos está aquí equilibrada, en cuanto a escenas costumbristas: pueden presenciarse dos bailes y canciones villanas, la primera en Barajas (vv. 693-712), pero la segunda en Madrid en casa de los protagonistas cortesanos, donde irrumpen los aldeanos con su folklore (vv. 2882-2897); mientras que la celebración de la entrada de la Princesa en las calles de Madrid es relatada con detalle por Benito a los aldeanos que quieren escucharle (vv. 959-1043). Por otro lado, el desarrollo del enredo

23. Para los aspectos relativos a las canciones utilizadas por Lope, véase Zanusso y Laplana [2013:657-658]. 
amoroso se reparte entre un espacio cercano a la huerta de Benito y la propia huerta, y la casa madrileña de Lisarda y su hermano. Si bien es cierto que en este segundo entorno se juega con los huecos y el primer piso de la galería, la función del espacio de representación rural no desmerece a la hora de propiciar conversaciones en aparte, alcahueterías entre los hermanos, ocultaciones de identidad mediante disfraces, mentiras para salir del paso..., es decir lances similares a los que se producen en los interiores en un contexto urbano.

Por otro lado, es cierto que se persigue un contraste de ambos mundos que queda reflejado, en la onomástica de los villanos protagonistas (Benita y Jacinto) y un motivo especialmente explotado en esta comedia, como es la oposición entre «hablar necio» $\mathrm{y}$ «hablar discreto», que los criados identifican como un rasgo distintivo de estatus («Lisarda hablará discreto / con don Carlos, yo en necio a ti», vv. 331-332), y también la propia protagonista:

JACINTA No me habléis de esa manera, que no lo entiendo, por Dios; bajaos a mi campo vos, pues no subo a vuestra esfera. （vv. 1557-1560)

Existe, además, una abundancia de parlamentos en los que se oponen aldea y corte:

Benito Ya sabéis que yo no soy pretendiente lisonjero, porque más precio una flor de un huertecillo que tengo, que cuantas riquezas cubren los doseles de sus techos. (vv. 1077-1082)

Sin embargo, la confrontación no es aquí tan sustancial para el desarrollo y desenlace de la acción como lo puede ser en las comedias de honor villano. Cinco años antes Lope había redactado El villano en su rincón, donde el mismo título alude, con una metonimia espacial evidente, a la trascendencia que tiene el orgullo de pertenencia a un estatus social, por bajo que este pueda parecer. De igual manera que entre 1605-1608 había ensalzado, y premiado en el desenlace, la vitalidad y nobleza de ca- 
rácter de las gentes del campo personificadas en Peribáñez, Casilda y su entorno. Cierto es que los personajes de supuesto origen rural de Al pasar del arroyo se reivindican también en varias ocasiones en oposición a los engaños de la corte:

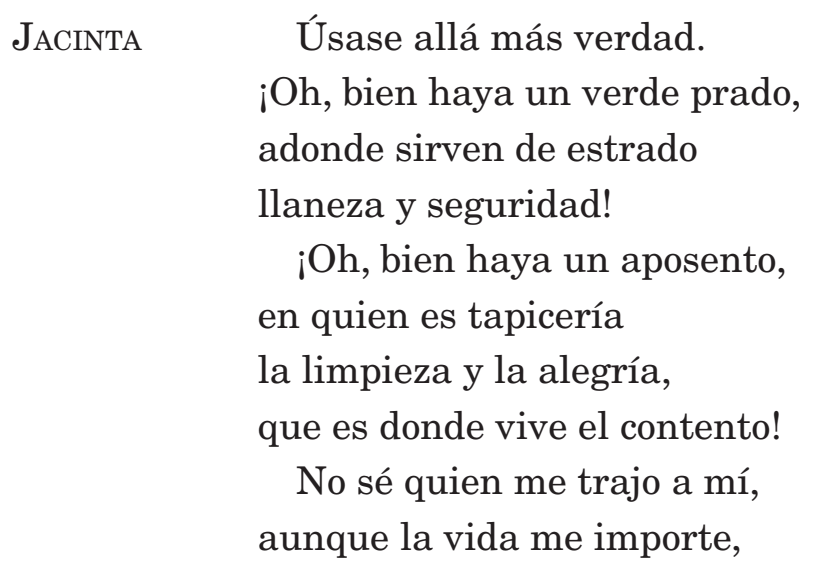

Pero no hay que olvidar que quienes así hablan resultan ser nobles, su condición se ha revelado pronto (al comienzo del segundo acto) y se destaca con frecuencia por su porte o, de nuevo, por su lenguaje, que les hace significativamente partícipes de ambos mundos:

\author{
Benito Y hablando con vos, es bien \\ que en lengua discreta sea; \\ cuando en el campo me vea \\ hablaré en necio también. \\ ¿No habéis visto que pretende \\ el vulgo en las cosas altas \\ poner muchas veces faltas, \\ porque es lengua que no entiende, \\ y que, en hablándole en necio, \\ celebra lo que entendió? \\ Pues de aquesta suerte yo \\ de entrambas lenguas me precio.
}

Por ello, el desenlace está perfectamente justificado y terminarán por integrarse en el contexto cortesano a través de sendos matrimonios, gracias al engaño 
urdido por uno de los galanes cortesanos. Por lo tanto, aunque pueda utilizarse como base el tópico de la alabanza de aldea y menosprecio de corte, la oposición se integra más en el juego dramático del fingimiento de la comedia de enredo, que en la lectura social de las comedias villanescas serias. Asimismo, a diferencia de los dramas de identidad oculta, la presencia e incluso la referencia a los progenitores nobles que pudieran incluso actuar como deus ex machina restaurando el orden, es puramente testimonial: solo conocemos el nombre y condición del padre de Jacinta y del padre de Benito. Tendrán, por tanto, la intervención imprescindible para dar autenticidad a este cambio de estatus, porque quien restablece los emparejamientos es uno de los implicados en el triángulo (o cuadrado) amoroso: don Luis, que no tiene más remedio que renunciar a Jacinta, al encontrarla en su aposento con don Carlos, a quien ella reconoce como su esposo.

Por lo tanto, la presencia de lo villano, que está certeramente utilizada e imbricada, parte del motivo tradicional del suceso del arroyo, permite dar cabida a la lírica tradicional, incluso a la métrica de este tipo de composiciones, y juega con un tópico, el de alabanza de aldea, que el público también podía disfrutar en clave desenfadada. Sin embargo, una vez más, destaca el conflicto amoroso, los celos, engaños y desengaños, basados en la casualidad y el ingenio de algún personaje (en este caso don Carlos) y aderezados con las identidades reveladas y las fingidas, que imponen el universo de la comedia urbana. Mientras, se busca una adaptación del espacio rural (calle de Barajas y huerta) al juego escénico que posibilite la dramatización de estos elementos de manera muy similar a la que se realiza en el contexto urbano.

\section{Conclusiones}

El análisis de las cinco comedias corrobora su pertenencia al género urbano como primera adscripción, pero la utilización del espacio rústico y la aparición de personajes y del contexto villanos ponen de manifiesto una hibridación, en la que existen algunos elementos reiterados. Entre ellos destacan el juego con las identidades fingidas u ocultas, que tiende un puente entre ambos mundos, generando lances muy productivos para el enredo; la utilización del contexto rural como un refugio para caballeros o damas en apuros y la preeminencia del espacio de representación sobre el espacio de ficción, que posibilita el desarrollo de los lances propios de la comedia 
de enredo en una gran ciudad, en un pueblo o incluso en el campo, una vez que se ha definido y fijado «un marco geográfico reconocible para la imaginación del espectador» (Arellano 1996:40).

Sin embargo, la utilización del contexto rural no es uniforme y depende de factores variados que inciden, o quizás sea mejor decir que se ven influidos por lo genérico. En primer lugar, es imprescindible atender a la cronología. Las tres primeras comedias analizadas, anteriores a 1600, dan muestras evidentes de pertenecer al primer Lope y, por lo que respecta al tema que nos ocupa, presentan un planteamiento totalmente utilitario de lo villano, que, no obstante, adopta materializaciones diversas en función de la tradición literaria por la que se decante Lope en cada caso, que es el segundo factor determinante que hay que contemplar. Así, en La serrana de Tormes los villanos, víctimas por su simpleza e ingenuidad son objeto de risa y burla, por lo que se inscriben en la línea evolutiva que delimita Hermenegildo [1995], desde el teatro cómico de finales del xv, con los autos y farsas primitivos, pasando por el teatro ruedesco del xvi, hasta desembocar en la creación del gracioso barroco. Por su parte, La serrana de la Vera, a pesar de tener su punto de partida en una base folklórica popular, se acerca hacia lo novelesco y pastoril, ${ }^{24}$ ofreciendo, por tanto, una visión más estilizada de la naturaleza, como interlocutora de las quejas de Leonarda y testigo de los desencuentros de la pareja protagonista. Es necesario distinguir este entorno natural del villanesco, también presente en esta obra como contexto secundario, necesario para el pleno desarrollo del carácter justiciero de esta serrana atípica. Los embustes de Celauro, la última de las tres obras primerizas, dando muestras de indeterminación genérica, juega con el riesgo trágico de los dramas de honor conyugal y empieza a hacer explícito el tópico de la alabanza de aldea, pero sin que argumentalmente resulte del todo creíble, toda vez que el desenlace, que implica el retorno a los orígenes de villano acomodado, parece inscribirse más en la casualidad azarosa que en la intención didáctica.

El salto significativo de la indeterminación genérica a la hibridación buscada y consciente puede apreciarse en La villana de Getafe y Al pasar del arroyo, las dos comedias fechadas en la segunda década del siglo, cuando el tema villano se había revestido de una nueva visión derivada de la necesidad de dignificar a una clase

24. Véanse estos elementos en el trabajo de Oleza [1986] sobre «La tradición pastoril en la comedia de Lope de Vega». 
social, la del villano acomodado, agente imprescindible en las nuevas directrices político-económicas, y la del campesino pobre, emigrado a la ciudad y posible público del corral.

Ni el teatro ni Lope podían desaprovechar la oportunidad derivada de esta nueva circunstancia socio-económica, que será el tercer factor clave en esta hibridación. Es en estas obras donde cobra sentido el tópico de alabanza de aldea, pero no tanto en su visión horaciana como en la que se apoya en la sangre limpia y el trabajo productivo que deben sanear la Corte. Estas dos últimas obras analizadas representan la vertiente cómica de los grandes dramas del poder injusto o de las villanescas serias, y se permiten jugar con los sueños de ascenso social de un espectador, o espectadora, que veía conseguir sus logros a una inteligente villana de Getafe y recuperar su posición a un orgulloso Benito que había vivido dignamente como un campesino acomodado. En ellas la imbricación del universo villano en el urbano está mucho mejor conseguida, gracias a la interacción de los personajes de ambos contextos, posibilitada por una presencia, más continuada, más significativa y mejor insertada en la trama, de los tipos urbanos en el espacio villano y viceversa.

A pesar de que la selección de estas cinco obras puede parecer, y lo es, limitada, el muestrario es significativo de los distintos modelos y motivaciones que llevan a Lope a subir a escena a los villanos en marcos genéricos esencialmente urbanos: villanos de los que reírse, villanos para ser utilizados, serranas urbanas y pastoriles que aúnan tradiciones, falsos y falsas villanas que esconden damas y caballeros veleidosos y villanos que reclaman su presencia en el escaparate teatral, mostrando catapultas de ascenso social, aunque sea por el escotillón. 


\section{BIBLIOGRAFÍA}

Antonucci, Fausta, «Teodoro y César Borgia una clave para la interpretación de $E l$ perro del hortelano, en Memoria de la palabra. Actas del VI Congreso de la Asociación Internacional Siglo de Oro. Burgos-La Rioja (15-19 julio 2002), eds. M.L. Lobato y F. Domínguez Matito, Iberoamericana, Madrid, 2004, pp. 263-274. ANTONUCCI, Fausta, «Organización y representación del espacio en la comedia urbana de Lope: unas calas», en El teatro del Siglo de Oro. Edición e interpretación, eds. A. Blecua, I. Arellano y G. Serés, Iberoamericana-Vervuert, Madrid-Frankfurt am Main, 2009, pp. 13-27.

Antonucci, Fausta, «Algunos ejemplos de hibridación genérica en el teatro de Lope: reflexiones al hilo de unas búsquedas en la base de datos ARTELOPE», Teatro de palabras, VII (2013), pp. 141-158.

ARATA, Stefano, «Casa de muñecas: el descubrimiento de los interiores y la comedia urbana en la época de Lope de Vega», en Las representaciones del espacio en el teatro del Siglo de Oro. Homenaje a Frédéric Serralta, eds. F. Cazal, C. González y M. Vitse, Iberoamericana-Vervuert, Madrid-Frankfurt am Main, 2002, pp. 91-115. Arellano Ayuso, Ignacio, «Convenciones y rasgos genéricos en la comedia de capa y espada», Cuadernos de Teatro Clásico (La comedia de capa y espada), 1 (1988), pp. 27-49.

ARellano Ayuso, Ignacio, «Sobre el modelo temprano de la comedia urbana de Lope de Vega», en Actas de las XVIII Jornadas de Teatro Clásico. Almagro 11, 12 y 13 de Julio de 1995, coords. F.B. Pedraza y R. González Cañal, Universidad de Castilla-La Mancha, Ciudad Real, 1996, pp. 37-60.

Bances Candamo, Francisco de, Theatro de los theatros de los passados y presentes siglos, ed. D.W. Moir, Tamesis Books, Londres, 1970.

BuEzo, Catalina, «Hacia una tipología del villano y lo villano en el teatro áureo», en La comedia villanesca y su escenificación, eds. F.B. Pedraza Jiménez, R. González Cañal, E.E. Marcello, Ediciones de la Universidad de Castilla-La Mancha, Ciudad Real, 2002, pp. 297-320.

CAMPBeld, Ysla, «Apertura estamental en La villana de Getafe», en Otro Lope no ha de haber. Atti del convegno internazionale su Lope de Vega, 10-13 febbraio 1999, ed. M.G. Profeti, Alinea Editrice, Firenze, 2000, pp. 131-38.

CortiJo, Adelaida, y Elizabeth Treviño SALAZAR, «Prólogo» a La villana de Getafe, 
en Comedias de Lope de Vega. Parte XIV, coord. J.E. López Martínez, Gredos, Madrid, 2015, vol. 1, pp. 240-253.

COUDERc, Christophe, «Quedar vacío el tablado: sobre el tiempo y la continuidad de la acción en dos comedias de Lope (El castigo sin venganza y La villana de Getafe)», en Similitud y verosimilitud en el teatro del Siglo de Oro. Coloquio internacional organizado por el laboratorio de investigaciones: lenguas y literaturas románicas. E.A. 1925, (PAU, 21 y 22 de noviembre de 2003), coord. I. Ibañez, EUNSA-Ediciones Universidad de Navarra, Pamplona, 2005, pp. 89-110.

DíEz Borque, José María, «Dos “villanas” para las tablas: Inés (La villana de Getafe); Doña María (La moza de cántaro)», Cuadernos de Teatro Clásico, 11 (1998a), pp. 31-51.

Díez Borque, José María, «De la villana que casó con noble», en Las mujeres en la sociedad española del Siglo de Oro: ficción teatral y realidad histórica: actas del II Coloquio del Aula-Biblioteca «Mira de Amescua», celebrado en Granada-Úbeda del 7 al 9 marzo de 1997 y cuatro estudios clásicos sobre el tema, eds. R. Castilla Pérez y J.M. Martínez Berbel, Universidad de Granada, Granada, 1998b, pp. 471-492. Díez Borque, José María, «Villanas reivindicadas en el teatro de Lope de Vega», en La comedia villanesca y su escenificación, eds. F.B. Pedraza Jiménez, R. González Cañal, E.E. Marcello, Ediciones de la Universidad de Castilla-La Mancha, Ciudad Real, 2002, pp. 155-180.

Escudero, Juan Manuel, «Espacio rural versus espacio urbano en las primeras comedias de Lope de Vega», en El espacio y sus representaciones en el teatro del Siglo de Oro, eds. F. Cazal, C. González y M. Vitse, Iberoamericana-Vervuert, Madrid-Frankfurt am Main, 2001, pp. 209-229.

González, Lola, «Prólogo» a La serrana de la Vera, en Comedias de Lope de Vega. Parte VII, coord. E. Di Pastena, Milenio-Universitat Autònoma de Barcelona, Lérida, 2008, vol. 3, pp. 1392-1409.

Hermenegildo, Alfredo, Juegos dramáticos de la locura festiva. Pastores, simples, bobos y graciosos del teatro clásico español, Oro Viejo, Palma de Mallorca, 1995. Ketan Menta, Dimita, «El retrato de la mujer en algunas de las obras de Lope de Vega», en Actas del I Congreso Ibero-Asiático de Hispanistas Siglo de Oro e Hispanismo general, Servicio de Publicaciones de la Universidad de Navarra, Pamplona, 2011, pp. 371-379.

MAGgi, Eugenio, «Prólogo» a La serrana de Tormes, en Comedias de Lope de Vega. Parte XVI, coords. F. d'Artois y L. Giuliani, Gredos, Madrid, 2017, vol. 2, pp. 135-141. 
Magnaghi, Serena, «Los conocimientos herméticos de los estudiantes salmantinos: los casos de La serrana de Tormes y La boda entre dos maridos de Lope de Vega», en De lo sobrenatural a lo fantástico. Siglos XIII-XIX, Biblioteca Nueva, Madrid, 2014, pp. 163-174.

Menéndez Pelayo, Marcelino, Estudios sobre el teatro de Lope de Vega, Consejo Superior de Investigaciones Científicas, Madrid, 1949.

Morley, S. Griswold, y W. Richard TyLer, Los nombres de personajes en las comedias de Lope de Vega. Estudio de Onomatologia, University of California Press, Berkeley (C.A.), 1961.

Morley, S. Griswold, y Courtney Bruerton, Cronología de las comedias de Lope de Vega, trad. M.R. Cartes, Gredos, Madrid, 1968.

OlEZA, Joan, «La propuesta teatral del primer Lope de Vega», Cuadernos de Filología, III 1-2 (1981), pp. 153-233.

OlEZA, Joan, «La tradición pastoril en la comedia de Lope de Vega», en Teatro y prácticas escénicas II: La comedia, coord. J.L. Canet Vallés, Tamesis Books, Londres, 1986, pp. 325-343.

OlEZA, Joan, «El primer Lope: un haz de diferencias», Cuadernos del Teatro Clásico, 8 (1997a), pp. 85-119.

OlezA, Joan, «Del primer Lope al Arte nuevo. Estudio preliminar» a Lope de Vega, Peribánez y el Comendador de Ocaña, ed. D. McGrady, Crítica, Barcelona, 1997b, pp. ix-lv.

OlEZA, Joan, «El Lope de los últimos años y la materia palatina», Criticón, LXXXVIILXXXVIII-LXXXIX (2003), pp. 603-620.

OlEZA, Joan, dir., ARTELOPE. Base de datos y argumentos del teatro de Lope de Vega, 2011- 2021, <artelope.uv.es>. Consulta del 2 de diciembre de 2021.

Pedraza Jiménez, Felipe B., «El extraño destino de las comedias villanescas», en $L a$ comedia villanesca y su escenificación, eds. F.B. Pedraza Jiménez, R. González Cañal, E.E. Marcello, Ediciones de la Universidad de Castilla-La Mancha, Ciudad Real, 2002, pp. 7-10.

Presotto, Marco, «Prólogo» a Los embustes de Celauro, en Comedias de Lope de Vega, Parte IV, coords. L. Giuliani y R. Valdés Gázquez, Milenio-Universitat Autònoma de Barcelona, Lérida, 2002, vol. 3, pp. 1221-1350.

RESTA, Ilaria, «La platera: un caso de contaminación en el sistema de géneros del primer teatro comercial», Anuario Lope de Vega. Texto, literatura, cultura, XXVI (2020), pp. 199-215. 
RozAS, Juan Manuel, Significado y doctrina del «Arte nuevo» de Lope de Vega, Sociedad General Española de Librería, Madrid, 1976.

RozAS, Juan Manuel, Lope de Vega y Felipe IV en el «ciclo de senectute». Discurso en la solemne apertura del Curso Académico 1982-1983, Universidad de Extremadura, Badajoz-Cáceres, 1982; reed. en Estudios sobre Lope de Vega, ed. J. Cañas Murillo, Cátedra, Madrid, 1990, pp. 73-131.

RUBieRa Fernández, Javier, La construcción del espacio en la comedia española del Siglo de Oro, Arco Libros, Madrid, 2005.

Salomon, Noël, Lo villano en el teatro del Siglo de Oro, Castalia, Madrid, 1985.

Shergold, Norman D., A History of the Spanish Stage, from Medieval Times until the end of the Seventeenth Century, The Clarendon Press, Oxford, 1967.

VEGA CARPIO, Lope de, Al pasar del arroyo, eds. B. Zanusso y J.E. Laplana Gil, en Comedias de Lope de Vega. Parte XII, coord. J.E. Laplana Gil, Gredos, Madrid, 2013, vol. 1, pp. 651-802.

Vega CARPio, Lope de, Los embustes de Celauro, Lope de, Comedias de Lope de Vega. Parte IV, coords. L. Giuliani y R. Valdés Gázquez, Milenio-Universitat Autònoma de Barcelona, Lérida, 2002, vol. 3, pp. 1221-1350.

Vega Carpio, Lope de, La serrana de la Vera, ed. L. González, en Comedias de Lope de Vega. Parte VII, coord. E. Di Pastena, Milenio-Universitat Autònoma de Barcelona, Lérida, 2008, vol. 3, pp. 1393-1519.

Vega Carpio, Lope de, La serrana de Tormes, ed. E. Maggi, en Comedias de Lope de Vega. Parte XVI, coords. F. d'Artois y L. Giuliani, Gredos, Madrid, 2017, vol. 2, pp. 135-288.

VEGa CARPIO, Lope de, La villana de Getafe, ed. J.M. Díez Borque, Orígenes, Madrid, 1990.

VEga CARPIo, Lope de, La villana de Getafe, eds. A. Cortijo y E. Treviño Salazar, Comedias de Lope de Vega. Parte XIV, coord. J.E. López Martínez, Gredos, Madrid, 2015, vol. 1, pp. 241-414.

WARDROPPER, Bruce W., «Lope de Vega's urban comedy», Hispanófila, 1 (1974), pp. 47-61. Weber de Kurlat, Frida, «Hacia una morfología de la comedia del Siglo de Oro», Anuario de Letras, XIV (1976), pp. 101-138.

Zanusso, Beatrice, y José Enrique LaPLANa GIL, «Prólogo» a Al pasar del arroyo, en Comedias de Lope de Vega. Parte XII, coord. J.E. Laplana Gil, Gredos, Madrid, 2013, vol. 1, pp. 649-802. 